\title{
Erratum: Monte Carlo investigation of the dosimetric effect of the Autoscan ultrasound probe for guidance in radiotherapy
}

Michael Martyn, Tuathan O'Shea, Emma Harris, Jeffrey Bamber, Stephen Gilroy, et al.

Michael Martyn, Tuathan O'Shea, Emma Harris, Jeffrey C. Bamber, Stephen Gilroy, Mark J. Foley, "Erratum: Monte Carlo investigation of the dosimetric effect of the Autoscan ultrasound probe for guidance in radiotherapy," Proc. SPIE 9790, Medical Imaging 2016: Ultrasonic Imaging and Tomography, 97902A (10 January 2017); doi: 10.1117/12.2271153

SPIE. Event: SPIE Medical Imaging, 2016, San Diego, California, United States 


\section{Erratum: Monte Carlo investigation of the dosimetric effect of the Autoscan ultrasound probe for guidance in radiotherapy}

Michael Martyn, National Univ. of Ireland, Galway (Ireland), Tuathan O'Shea, Emma Harris, Jeffrey Bamber, Stephen Gilroy, Institute of Cancer Research (United Kingdom) and Royal Marsden NHS Foundation Trust (United Kingdom), and Mark J. Foley, National Univ. of Ireland, Galway (Ireland)

Proc. SPIE 9790, Medical Imaging 2016: Ultrasonic Imaging and Tomography, 97900N (April 1, 2016); doi: 10.1117/12.2216653

Online Publication Date: 1 April 2016

Revised: 10 January 2017

Conference Date: 28-29 February 2016

Conference Location: San Diego, California, United States

Conference Title: Medical Imaging 2016: Ultrasonic Imaging and Tomography

Conference Chairs: Neb Duric, Brecht Heyde

A revised version of this paper, originally published on 1 April 2016, was published on 10 January 2017. To correct for a set-up error, the simulated treatment plan was re-run using CT images of a solid water phantom with/without the Autoscan ${ }^{\mathrm{TM}}$ US probe in contact with its surface. The revised paper is available at http://dx.doi.org/10.1117/12.2216653.

Changes to original proceedings:

Section 2.2

1. A solid water phantom is employed as opposed to a Rando phantom.

2. Figure 1 is changed to illustrate new phantom.

Section 2.3

1. New treatment isocentre.

2. Figure 3 is changed to illustrate dose distribution in new phantom.

Section 3.2

1. Text of first paragraph has been revised to reflect new results.

2. Table 2 has been revised to reflect new results.

3. Figure 6 has been revised to reflect new results.

Section 4

1. Text of second paragraph has been revised to reflect new results. 